Person-environment fit

The conundrum of person-environment fit/misfit: A world of possibilities

\author{
Kleinjan Redelinghuys \\ North-West University
}

Correspondence: 21887217@nwu.ac.za 


\title{
The conundrum of person-environment fit/misfit: A world of possibilities
}

\begin{abstract}
The importance of studying person-environment (PE) interactions needs no introduction, as good fit generally leads to positive outcomes, while misfit usually leads to negative consequences. Even though an extensive knowledge base has been built around the concept of PE fit, numerous studies suggest that we have only partially tapped into its full potential. This warrant further exploration of this construct. Therefore, this article aimed to reflect on previous PE fit literature (its background, importance, dimensionality, common obstacles) and use it as a framework to direct attention to possibly underexplored areas of fit. Based on the foundations of previous PE fit literature, numerous conclusions regarding fit are reached, practical implications regarding fit are discussed, and recommendations for future fit research are made. Although there may be incongruence regarding the direction of PE fit, its dimensionality, measurement, and the way forward (to name a few); one thing is for sure: we live in exciting times of fit research!
\end{abstract}

Keywords: Person-environment fit, person-group fit, person-job fit, person-organization fit, person-supervisor fit, demands-abilities fit, needs-supplies fit 
Person-environment fit

\section{Introduction}

The importance of studying person-environment (PE) interactions needs no introduction. PE fit is a dominant construct in a wide array of fields (e.g., management, personnel psychology, organizational behavior), as the onus of addressing misfit or reinforcing fit may trigger the involvement of various organizational functions (e.g., management, human resource department, industrial/organizational psychology functions) during different stages of employment (e.g., preemployment, post-employment). This comes as no surprise owing to the ripple effect PE fit (or misfit) may have on essential outcomes related to the individual, group, supervisor, and organization. Irrespective of the type of fit under investigation, good fit predominantly results in positive outcomes (e.g., Kristof-Brown, Zimmerman, \& Johnson, 2005), while misfit usually leads to negative consequences (e.g., Follmer, Talbot, Kristof-Brown, Astrove, \& Billsberry, 2018). Even though a large PE fit knowledge base exists, numerous studies (e.g., Darrow \& Behrend, 2017), suggest that we have only partially tapped into its full potential. This warrant further exploration of this construct. Therefore, the article aims to reflect on previous PE fit literature (its background, importance, dimensionality, common obstacles) and use it as a framework to direct attention to possibly underexplored areas of fit.

\section{Person-environment fit}

PE fit is fundamentally rooted in Lewin's (1951) interactionist theory, which suggests that behavior transpires as individuals and environments interact, with both parties bringing specific characteristics into the equation. Therefore, within the work domain, PE fit can broadly be defined as the congruence between employee characteristics and work environment characteristics (Jansen \& Kristof-Brown, 2006). From an employee perspective, and depending on the type of fit, some characteristics may include abilities, goals, needs, personality, skills, and values (e.g., Chuang, 
Person-environment fit

Shen, \& Judge, 2016). Similarly, from the work environment perspective, some characteristics may include culture, demands, goals, supplies, and values (e.g., Beasley, Jason, \& Miller, 2012). Therefore, PE fit embodies complementary and supplementary fit perceptions (Kristof, 1996; Muchinsky \& Monahan, 1987). Complementary fit arises when an individual (through the characteristics which he or she possesses) can fill a void experienced by the organization or another environmental role-player (e.g., job), or when the organization or another environmental roleplayer (through the characteristics it possesses) can fill a void experienced by the employee, or both (Kristof, 1996; Muchinsky \& Monahan, 1987). The two dimensions most suited to this framework include demands-abilities (DA) and needs-supplies (NS) fit (Chuang, Hsu, Wang, \& Judge, 2015). Although some studies integrate the preceding dimensions into person-job (PJ) fit (e.g., Brkich, Jeffs, \& Carless, 2002), Cable and DeRue (2002), established that these are distinct concepts. DA fit reflects the congruence between an employee's abilities and the demands encountered in his or her job (Edwards, 1991). NS fit demonstrates the congruence between an employee's needs and the supplies his or her job provides (Edwards, 1991).

In contrast to complementary fit perceptions, supplementary fit arises when an employee possesses characteristics (e.g., values, goals) that are congruent with a particular comparison group within the environment (Muchinsky \& Monahan, 1987). This comparison group may include the employee's organization, his or her supervisor, and his or her work group. While personorganization (PO) fit reflects the congruence between an employee and his or her organization based on selected criteria (e.g., goals), person-group (PG) fit, and person-supervisor (PS) fit reflects the congruence between an employee and other people (workgroup and supervisor) in the organization based on predetermined criteria (e.g., Kristof-Brown et al., 2005). Thus, the latter takes an interpersonal stance on fit. Although both are interpersonally inclined, PG fit (as opposed 
Person-environment fit

to PS fit) is not inherently indicative of dyadic fit (Kammeyer-Mueller, Schilpzand, \& Rubenstein, 2013). Despite its interrelatedness, complementary and supplementary fit have different underlying assumptions, which enable both to relate to outcomes independently (Cable \& Edwards, 2004). Therefore, it is vital to focus on both types of fit, as being fixated solely on supplementary fit may result in excessive homogeneity (Schneider, Goldstein, \& Smith, 1995).

The preceding fit perceptions can be measured from a perceived, subjective, and objective perspective. Confusion regarding the distinction between perceived and subjective fit perceptions has resulted in the interchangeable use of the two (Kristof-Brown et al., 2005). Kristof-Brown et al. (2005) however proposed that it can be distinguished as follows: "(a) perceived fit, when an individual makes a direct assessment of the compatibility between $\mathrm{P}$ and $\mathrm{E}$; (b) subjective fit, when fit is assessed indirectly through the comparison of $\mathrm{P}$ and E variables reported by the same person" (p. 291). Despite arguments about the objectivity of objective fit, it reflects the 'actual' fit between employees and their environment as determined through different sources (Verquer, Beehr, \& Wagner, 2003). Although slightly different in their conceptualization (atomistic, molecular, and molar approach), Edwards, Cable, Williamson, Lambert, and Shipp's (2006) article can be consulted for examples on how the different perspectives have been applied in PE fit research. Although one approach (e.g., subjective) to fit may be superior to another (e.g., objective) under certain circumstances (see Cable \& Judge, 1996), each perspective may serve some purpose depending on the type of information one would like to gather.

\section{Dimensions of PE fit}

Regardless of the content dimensions associated with different types of fit, the current section will separately focus on PO, PJ (inclusive of DA and NS), PG, and PS fit. Although the author does not discredit other types of fit (e.g., person-vocation fit), the categories of fit selected for the current 
Person-environment fit

study are viewed as good representations of the construct. Background information and factors related to each sub-dimension are discussed.

Person-organization fit. PO fit has been defined from a complementary and supplementary perspective (e.g., Kristof, 1996), with the latter (specifically regarding values congruence) receiving the most attention. In contrast, the complementary viewpoint has received minimal research attention (Piasentin \& Chapman, 2006). This may be attributed to the confusion or disagreement regarding PO fit's conceptualization (e.g., what it should entail), forcing metaanalytic studies (Hoffman \& Woehr, 2006; Verquer et al., 2003) to group its content dimensions into values congruence and 'other congruence' (e.g., goals, personality). Applying DA and NS fit to the job context as opposed to the organizational context (as initially proposed by Muchinsky \& Monahan, 1987) may also be a reason for this. Nevertheless, PO fit research has focused on numerous criteria for assessing congruence, covering characteristics (or combined characteristics) such as demands-abilities (e.g., Kristof, 1996), goals (e.g., Vancouver \& Schmitt, 1991), needssupplies (e.g., Darrow \& Behrend, 2017), personality (e.g., Saks \& Ashforth, 1997), and values (e.g., Cable \& DeRue, 2002).

Using some of the preceding criteria, PO fit has influenced burnout, intent to quit, job satisfaction, organizational citizenship behavior, organizational commitment, psychological need satisfaction, task performance, and turnover (Andela \& Van der Doef, 2018; Greguras \& Diefendorff, 2009; Hoffman \& Woehr, 2006; Kristof-Brown et al., 2005). Although PO fit links to variables at various nested levels, numerous studies (Cable \& DeRue, 2002; Kristof, 1996; Kristof-Brown et al., 2005) suggest that it should have the most significant impact on organizational-related criteria. Hoffman and Woehr (2006) however found a stronger association between PO fit and task performance (job-related) in comparison to organizational citizenship 
Person-environment fit

behavior (organizational-related). Therefore, this assumption may necessitate further investigation.

Person-job fit. PJ fit has been defined from a complementary and supplementary perspective (e.g., Darrow \& Behrend, 2017), with the former receiving the most attention. This may be ascribed to uncertainty regarding PJ fit's conceptualization and what it should encompass (e.g., complementary and supplementary fit, or just the latter; should DA and NS fit be separate, or should it form part of one construct). Nevertheless, PJ fit research has focused on several criteria for evaluating fit, including characteristics (or combined characteristics) such as demands-abilities (e.g., Edwards, 1991), needs-supplies (e.g., Cable \& DeRue, 2002), goals, personality, and values (e.g., Darrow \& Behrend, 2017). Using some of the preceding criteria, PJ fit (in its 'entirety', as well as separately as DA and NS fit) has impacted essential outcomes such as career satisfaction, intent to quit, competence need satisfaction, job performance, job satisfaction, meaningfulness, occupational commitment, and organizational commitment (Cable \& DeRue, 2002; Edwards, 1991; Greguras \& Diefendorff, 2009; Kristof-Brown et al., 2005; Tims, Derks, \& Bakker, 2016). Although PJ fit has been linked to variables at various nested levels, numerous studies (KristofBrown et al., 2005; Lauver \& Kristof-Brown, 2001), suggest that it should have the biggest impact on job-related criteria. Whether PJ fit consistently relates to job-related criteria above and beyond other types of fit remains to be seen.

Person-group fit. PG fit has been defined from a complementary and supplementary perspective (e.g., Darrow \& Behrend, 2017), with the latter receiving the most attention. Disputes surrounding PG fit's conceptualization and what it should cover (e.g., complementary and supplementary fit, or just the latter) may be the reason for this. Nevertheless, PG fit research has focused on numerous criteria for measuring fit, incorporating characteristics (or combined 
Person-environment fit

characteristics) such as demands-abilities (e.g. Darrow \& Behrend, 2017), goals (e.g. KristofBrown \& Stevens, 2001), lifestyle (e.g. DiMarco, 1975), needs-supplies (e.g. Darrow \& Behrend, 2017), personality (e.g. Seong \& Kristof-Brown, 2012), values (e.g. Adkins, Ravlin, \& Meglino, 1996), and work style (e.g. Kristof-Brown, Jansen, \& Colbert, 2002). Using some of the preceding criteria, PG fit has been linked to co-worker satisfaction, contextual performance, group cohesion, job satisfaction, leader-rated group performance, and relatedness need satisfaction (Greguras \& Diefendorff, 2009; Kristof-Brown et al., 2005; Seong, Kristof-Brown, Park, Hong, \& Shin, 2015). Although PG fit has been associated with variables at various nested levels, some evidence (e.g., Kristof-Brown et al., 2005) suggests that it should have the greatest impact on group-related criteria. Whether PG fit consistently relates to group-related criteria above and beyond other types of fit remains to be seen.

Person-supervisor fit. PS fit has been defined from a complementary and supplementary perspective (e.g., Darrow \& Behrend, 2017), with the latter receiving the most attention. This may be ascribed to ambiguity regarding PS fit's conceptualization and the aspects it should measure (e.g., complementary and supplementary fit, or just the latter). Nevertheless, PS fit research has focused on numerous criteria for calculating fit, covering characteristics (or combined characteristics) such as demands-abilities (e.g. Darrow \& Behrend, 2017), goals (e.g. Witt, 1998), lifestyle (e.g. DiMarco, 1974), leadership style (e.g. Chuang, Judge, \& Liaw, 2012), personality (e.g. Schaubroeck \& Lam, 2002), supplies-values (e.g. Marstand, Martin, \& Epitropaki, 2017), values (e.g. Hoffman, Bynum, Piccolo, \& Sutton, 2011), and work style (e.g. Turban \& Jones, 1988). Using some of the preceding criteria, PS fit has been linked to affective organizational commitment, burnout, job satisfaction, leader-member exchange, relatedness need satisfaction, supervisor satisfaction, and turnover intention (Andela \& Van der Doef, 2018; Astakhova, 2016; 
Person-environment fit

Kristof-Brown et al., 2005). Although PS fit has been associated with variables at various nested levels, some evidence (e.g., Kristof-Brown et al., 2005) suggests that it should have the biggest impact on supervisor-related criteria. Whether PS fit consistently relates to supervisor-oriented criteria above and beyond other types of fit remains to be seen, especially when the small PS fit knowledge base that currently exists is taken into consideration.

\section{Multidimensionality of fit}

A great deal of studies (e.g., Kristof-Brown et al., 2005; Tak, 2011) has called for the multidimensional assessment of PE fit. This has led to the development of various PE fit models and measures (e.g., Beasley et al., 2012; Cable \& DeRue, 2002; Chuang et al., 2016; Darrow \& Behrend, 2017; Edwards \& Billsberry, 2010; Herdman \& Carlson, 2009; Jansen \& Kristof-Brown, 2006). Unfortunately, most of these models have largely wandered off into different directions regarding the number of fit dimensions, the types of fit, the content dimensions included for subdimensions of fit, the samples used, the format of measurement (e.g. subjective, objective, perceived), and how one should model fit (e.g. aggregate vs superordinate). This has led to various obstacles in fit research. Despite these discrepancies, some of these models can still be helpful depending on the type of information one wants to gather or as stepping stones in the development of future PE fit models.

\section{Common obstacles in PE fit studies}

Some of the common obstacles encountered in PE fit studies include:

Measures using doubled-barrelled questions. Often across different levels of measurement and content dimensions.

Assessing one dimension of fit (e.g., PO fit), however doing so in a manner that could be classified as another fit dimension (e.g., PG fit). 
Person-environment fit

Not assessing fit in a commensurable manner.

$>$ Focusing on one sub-dimension (e.g., PO fit) or perspective (e.g., complementary) of fit at the expense of other viable alternatives (e.g., PS fit / supplementary fit) without a sound explanation.

Focusing on one content dimension (e.g., values) at the expense of others (e.g., goals) without a good rationale.

The predominant focus on cross-sectional data, which does not consider the dynamic nature of fit.

$>$ Uncertainty whether each fit dimension should be assessed from a complementary and supplementary perspective.

$>$ Few studies that use comprehensive frameworks to explain the complexity of PE fit and how different types of fit can uniquely relate to other variables.

The inconsistent use of PJ, DA, and NS fit.

The widespread diversity in the multidimensionality of PE fit models.

The fixation on traditional theories to explain PE fit phenomena.

Fixation on a small set of criteria related to PE fit phenomena.

The predominant assessment of PE fit outside of cross-cultural frameworks.

$>$ Promising, but largely untested assumptions that may require further investigation. For example, PE fit dimensions relate the strongest to qualitatively similar constructs (KristofBrown et al., 2005, Oh et al., 2014).

\section{Areas that may require further investigation}

Acknowledging the common obstacles faced by prior studies, the current section will pose numerous questions that may warrant further inspection within the PE fit context. 
Person-environment fit

\section{What could determine if a certain type or content dimension of fit will be important}

for an employee? Individual differences (e.g., culture, orientation to work, personality, values) could determine the importance employees attach to certain types of fit. Personality traits (or combination of traits) should influence PE fit to varying degrees. Utilizing the five-factor model (FFM), extroverted (vs. introverted) employees should theoretically place a stronger emphasis on interpersonal fit types (PG / PS). This could be due to their social inclination, as they enjoy working in groups, and derive energy from human interaction (Goldberg, 1990; McCrae \& Costa, 1999). Similarly, agreeable employees should theoretically value interpersonal fit types, as they are considerate, friendly, and helpful (amongst others). These are all ingredients for being good team players. Applying Holland's (1997) RIASEC model, investigative and realistic (vs. enterprising and social) employees should theoretically value PJ fit above interpersonal fit, as both like to work independently, and prefer to work with things rather than people.

Culture (e.g., see Oh et al., 2014) and values should influence PE fit to varying degrees. Utilizing Hofstede's (1980) framework, collectivistic (vs. individualistic) people should theoretically place a stronger emphasis on interpersonal fit types (PG / PS), as they are groupfocused. In contrast, using Schwartz's (1999) framework, people who lean toward mastery (vs. harmony), should theoretically value PJ fit above interpersonal fit, as they are concerned with selfenhancement. Depending on an employee's orientation to work (job, career, calling), certain employee needs or organizational supplies may also be more crucial than others to achieve congruence. Job-oriented employees should predominantly value monetary gain; career-oriented employees achievement and advancement; and calling-oriented employees should be intrinsically motivated (Wrzesniewski, McCauley, Rozin, \& Schwartz, 1997). Therefore, although NS fit may be important for people regardless of their orientation to work, the content dimension (e.g., the 
type of need) on which congruence should be achieved, should differ. Other factors (e.g., generational differences, job position, psychopathology, work centrality) should also influence the emphasis employees place on different elements of their job (e.g., Cennamo \& Gardner, 2008).

What could influence people to enter incongruent jobs? Various factors could coerce people into accepting incongruent jobs. Different role-players (e.g., family members, teachers) may affect children's subject choices in school, their training and education after school, and subsequently the line of work they enter. These role-players may guide children away from certain occupations based on their own beliefs (e.g., one would never make a good living as a musician), regardless of the skills children may possess (e.g., having exceptional artistic skills). Similarly, role-players may guide children into specific occupations based on their own beliefs (e.g., a man should be able to work with his hands), despite children having no preference for it.

Furthermore, although people's interests and abilities may match particular jobs, they may disregard certain types of work, due to preconceived ideas associated with occupations or industries (e.g., Miller \& Hayward, 2006). These ideas could be influenced by one's community, culture, lived experiences, schooling system, and media to name a few. Accordingly, people may frown upon certain occupations based on gender (e.g., HEED fields are for women and STEM fields for men), generalized characteristics associated with people in the profession (e.g., lawyers are dishonest), sexual orientation (e.g., only homosexual men engage in traditionally female occupations), and social standing (e.g., 'dirty' work is reserved for people with low social standing).

A lack of work volition should also influence employment decisions. Numerous factors can affect work volition, including (but not limited to) socio-economic factors, economic conditions, and legislation (Blustein, 2006; Duffy, Blustein, Diemer, \& Autin, 2016). Socio- 
Person-environment fit

economically, although some people may meet the minimum requirements to enter tertiary education, some may not have the financial means to do so. Economically, countries or areas may be plagued with low economic growth and high unemployment rates that limit employment opportunities. Regarding legislation, local laws may restrict people from entering specific jobs or reserve it for designated people (e.g., employment equity). Most of the preceding factors could force employees to select jobs based on availability, as they will not necessarily have the privilege of pursuing jobs that match their personal characteristics. As the preceding discussion shows, numerous factors can pressure people into taking incongruent jobs. Therefore, organizations should have the necessary contingency plans in place to address the inevitability of misfit.

What could influence organizations to employ incongruent employees? Apart from people taking on incongruent jobs, organizations may also be forced to appoint incongruent employees under certain circumstances. A skills gap might exist between the skills organizations require and the skills predominantly produced through educational and training institutions in specific countries or regions. This may pressure organizations to make selection decisions based on who would experience the least amount of misfit (compared to others) as opposed to who would fit the best. Furthermore, organizations may be forced to adhere to local legislation or policies to procure government contracts and enhance their corporate social responsibility. This may pressure organizations to select employees based on personal characteristics (e.g., disability, gender, race, employees living within the proximity of the organization's operations) and not necessarily on criteria related to fit. Volatile economic conditions accompanied by high unemployment may also pressure organizations to make selection decisions based on 'what they can get' as opposed to 'what they would prefer.' 
Person-environment fit

What could trigger employees to reassess their fit? Various changes in one's environment can trigger employees to re-evaluate their fit (Caldwell, Herold, \& Fedor, 2004; Follmer et al., 2018). Restructuring can impact one's job design through job demotion, enlargement, promotion, and rotation (amongst others). Where one previously experienced good DA fit, a demoted employee's abilities may suddenly exceed the demands of his or her job. Similarly, a promoted employee's demands may suddenly exceed his or her abilities. Additionally, alterations (of any kind) to one's job design could result in an imbalance between the desired needs of employees and the supplies provided by the organization. For example, an employee who values autonomy could be demoted to a position with restricted autonomy. Similarly, an employee who does not value relatedness could get promoted to a highly sociable position. Therefore, something that may initially be perceived as positive (e.g., promotion) will not necessarily result in positive PE fit outcomes (Follmer et al., 2018). Organizational cost-cutting procedures can also influence one's job in the form of remote working (e.g., to save on office space or office equipment) for instance. Extraverted people, who thrived because of frequent interpersonal contact at work, may be forced into a more depersonalized work setting in the form of remote working.

Furthermore, technological advancements (e.g., artificial intelligence) may eliminate the human component from various tasks. This could positively influence employees, for example, the automation of dreaded monotonous tasks may alleviate certain demands inherent to an employee's job. From a negative perspective, it may interfere with employees' autonomy. A change in management or immediate supervisors may also influence aspects of one's job. New managers may delegate more of their work, which could place additional demands on employees; especially if employees find these tasks undesirable. In contrast, new managers may delegate less of their work, providing certain employees with fewer opportunities to utilize the skills that make them fit 
Person-environment fit

well with their job. Mergers and acquisitions can also evoke fit perceptions. One may have closely identified with one's organization, but due to circumstances a change of ownership or merge with another organization occurs. Accordingly, the 'new' organization may not necessarily embody the values or practices that made you fit well with your original organization. Isolated events or misunderstandings could perhaps also trigger unwanted reassessments of fit. A negative performance review may cause an employee to reassess his or her DA fit.

Some dissimilarities (surface-level) between employees and their environment are also easier to detect than others (deep-level) (Bell, 2007). Consequently, one may only become aware during a later stage that your supervisor or colleagues possess certain characteristics that may strongly go against your belief system. For example, highly religious individuals may strongly disapprove of factors such as alcohol consumption, body art, and homosexuality. Suddenly, three months down the line at the year-end function, they meet their female supervisor's tattooed wife for the first time and gain first-hand experience of their drinking habits. Similarly, one may only later realize that your supervisor or colleagues affiliate themselves with a cause, cult, or political party which you despise. This may create doubt regarding the perceived degree of similarity that exists. Furthermore, a lack of fit in one dimension may also trigger movements in other fit dimensions. For example, when employees experience lower than the desired amount of DA or PG fit, they should start to develop needs (e.g., need for coaching, need for better communication) related to the dimension where incongruence is experienced (influencing their NS fit). When their need is attended to (e.g., the employee received coaching), this should influence their NS fit, and subsequently their DA fit. This illustrates the interrelated nature of PE fit perceptions and the need for conducting longitudinal studies. 
Person-environment fit

How can different types of fit uniquely relate to outcomes? Most studies (with a few exceptions, e.g., see Harold, Oh, Holtz, Han, \& Giacalone, 2016) have assessed isolated accounts of PE fit with a handful of outcomes without much consideration of how different types of fit can uniquely relate to criteria. Therefore, the current section will aim to emphasize the importance of distinguishing between different types of fit. This will be done from a fit, followed by a misfit perspective.

Social psychologists suggest that people seek to express themselves in a manner that genuinely echoes their personal characteristics (Swann, Stein-Seroussi, \& Giesler, 1992). Sheldon, Ryan, Rawsthorne, and Ilardi (1997) propose that authenticity can vary across the roles one occupy. Therefore, the degree to which a person can act authentically will be influenced by the environment in which the person functions (Van den Bosch \& Taris, 2014). In line with Jansen and Kristof-Brown's (2006) nested PE fit model, this environment can include the person, his or her job, group, supervisor, and organization. Therefore, in the context of PO fit, it is reasonable to suggest that similarity based on popular congruence factors (e.g., goals, values), would allow an employee to act authentically within his or her organization. Furthermore, fit could also have a stronger predictive effect on positive outcomes (e.g., Oh et al., 2014) that are qualitatively similar to the fit dimension under investigation (e.g., Kristof-Brown et al., 2005).

Thus, PO fit may not only allow employees to act authentically, but in the process also positively influence organizational-focused criteria such as organizational commitment, organizational citizenship behavior towards the organization, and organizational identification. Similarly, congruence on interpersonal types of fit may allow employees to act unpretentiously towards their colleagues and supervisor. This may subsequently have a positive effect on grouprelated criteria such as cohesion, relatedness satisfaction, role clarity, satisfaction with co-workers, 
Person-environment fit

and organizational citizenship behaviors towards one's group. Regarding PS fit, good fit could allow employees to act authentically, which could in turn influence positive supervisor-related criteria such as leader-member exchange, satisfaction with supervisor, and constructive evaluations of leader behaviors or leadership styles.

Similar to supplementary fit perspectives, complementary fit could also have a stronger predictive effect on positive outcomes (e.g., Oh et al., 2014) that are qualitatively similar to the fit dimension under investigation (e.g., Kristof-Brown et al., 2005). Although DA and NS fit relate to job-related criteria, both are distinct concepts (Cable \& DeRue, 2002; Hinkle \& Choi, 2009). Therefore, the mechanisms through which they may affect outcomes and the unique factors they may bring into the equation should potentially differ. Various outcomes may emerge when NS fit is experienced. When there is symmetry between what employees crave from their jobs and what their job essentially offers, it paves the way for need-fulfillment and satisfaction (Arthur, Bell, Villado, \& Doverspike, 2006). Depending on the need under investigation (e.g., whether it is aligned with intrinsic or extrinsic rewards) and how it is conceptualized, different needs may trigger different outcomes. Within the PE fit framework, needs may reflect wants or desires stemming from learned motives or socialization as opposed to innate or essential biological needs (Baard, Deci, \& Ryan, 2004; Cable \& Edwards, 2004).

In contrast, needs from a self-determination theoretical perspective (autonomy, competence, relatedness) may reflect needs that are "innate, essential, and universal" (Ryan \& Deci, 2000, p. 74). Although disagreements regarding the universality of needs may exist (e.g., Carver \& Scheier, 2000), employee needs are undeniably diverse and context-specific. Therefore, the fulfillment and satisfaction of these specific needs will depend on diverse, yet qualitatively similar supplies which consider the employee's environment. For example, the need for 
Person-environment fit

competence will only be satisfied when training is aimed at addressing the exact area in which the employee has a perceived competence deficiency. Although some studies have shown how specific needs relate to different criteria (e.g., Greguras \& Diefendorff, 2009), there is probably room for much more exploration in this area, especially in terms of assessing specific needs and supplies, and their unique effect on outcomes.

Regarding DA fit, when employees are equipped with the necessary toolkits to effectively conquer their job demands, positive outcomes will ensue. Higher self-efficacy may occur, as individuals should have more confidence in their ability to effectively deal with their environment (Bandura, 1986). From a psychological well-being perspective, good DA fit could allow employees to efficiently manage the situation (environmental mastery) in which they function (Ryff \& Keyes, 1995). Regarding self-determination theory, employees should experience competence satisfaction, as good DA fit would allow them to master environmental challenges (Deci \& Ryan, 1985). Furthermore, good DA fit would suggest that employees have the necessary skills to do their job well. This may afford employees opportunities for trait activation and strength utilization which could positively influence their self-confidence and self-esteem. Although the preceding discussion refers to job demands in general (which is common in PE fit literature), demands can also be more specific. Depending on one's frame of reference and the occupation under investigation, numerous job demand categories may exist: cognitive, emotional, physical, psychological, and social (Demerouti \& Bakker, 2011; Diefendorff, Greguras, \& Fleenor, 2016). Within-category distinctions can also be made depending on the job one occupies. For example, the physical demands experienced by surgeons (and the physical abilities to deal with their demands) should fundamentally differ from those of lumberjacks.

The triple-match principle (de Jonge \& Dormann, 2006) suggests that job demands and job 
Person-environment fit

resources interact the most when all variables of concern (demands, resources, strains) are qualitatively similar (e.g., they are affect-based). Longitudinally, de Jonge and Dormann (2006) found that high demands and low resources predicted different strain outcomes over a two-year period. Applying de Jonge and Dormann's (2006) principle, it is reasonable to suggest that positive outcomes will emerge when employees experience similar demand and resource levels. In the context of PE fit, however, resources should then refer to knowledge, skills, abilities, and other characteristics (e.g., certain personality traits). Therefore, when employees have the physical prowess (e.g., hand dexterity, endurance) to sufficiently deal with their physical job demands (e.g., long hours), they may be more energetic, precise in their work, and display better safety behaviors. Similarly, when employees have the emotional capacity to conquer their emotional demands (e.g., emotional intelligence), it may lead to increased emotional well-being, positive affect, and positive coping behaviors. Therefore, depending on the demand under investigation and the presence or absence of the ability needed to conquer it, different outcomes may arise. Although some studies have shown how specific job demands (within the DA fit context) relate to various criteria (e.g., Diefendorff et al., 2016; Park, Beehr, Han, \& Grebner, 2012), there is room for much more exploration in this area, especially with regard to assessing specific abilities and demands, and their unique effect on outcomes.

Misfit can be divided into two categories: 1) experiencing higher than the desired amount of fit (overfit), and 2) experiencing less than the desired amount of fit (underfit). Both perspectives should predominantly negatively impact employees.

When employees experience higher than the desired amount of supplementary fit, it poses the risk of excessive homogeneity (Schneider et al., 1995). Consequently, this could lead to uniform cognitive and behavioral patterns, which may promote undesirable outcomes such as 
Person-environment fit

inadaptability, resistance to change, as well as stagnant thinking and decision-making (Meglino \& Ravlin, 1998; Schneider, 1987). Unique outcomes may also accompany excessive fit on different supplementary fit dimensions. Too much PS fit may perhaps lead to preferential treatment of some employees over others (e.g., being more lenient towards some employees). Similarly, too much PG fit may also lead to preferential treatment of specific group members over others (e.g., being more tolerant towards the social loafing of particular group members). Additionally, too much PO fit may lead to a loss of personal identity.

In contrast, when employees experience lower than the desired amount of supplementary fit, they may experience a sense of alienation, detachment, exclusion, frustration, and victimization from the environment (group, organization, supervisor) where misfit is experienced (Follmer et al., 2018; Harold et al., 2016; Salmivalli, Lagerspetz, Björkqvist, Österman, \& Kaukiainen, 1996; Thomson \& Wendt, 1995). This may be ascribed to the lack of commonalities shared between the person and his or her environment, as people are generally attracted to organizations and people that they have something in common with (Byrne, 1971; Schneider, 1987). In response to this misfit, and depending on the type of misfit experienced, various factors may prompt employees to respond positively or negatively to their situation. Some employees may participate in counterproductive or withdrawal behaviors, while others may engage in job crafting behaviors (e.g., relational crafting) to create better PG fit. Therefore, although misfit is predominantly negatively perceived, it could also spark positive change (Follmer et al., 2018).

Although employees may be motivated by some imbalance between themselves and their job demands (Argyris, 1964), excessive demands should negatively impact them. In line with the demand categories listed earlier (e.g., Demerouti \& Bakker, 2011) and the triple-match principle (de Jonge \& Dormann, 2006), when one's physical demands overshadow one's physical abilities, 
Person-environment fit

physical strain should occur. For example, when an employee does not have the strength or endurance to operate heavy machinery for a reasonable period, the employee may be more accident or injury prone due to fatigue. Similarly, when an employee does not have the necessary skills to continuously shrug off the insults flung their way by clients or patients, the employee may become anxious, depressed, stressed, and engage in negative coping behaviors. In contrast, when employees' abilities exceed their demands, they are likely to experience boredom (Park et al., 2012). Qualitative (routine and simple tasks) and quantitative (too little work) underload are some of the factors that create boredom (Bruursemaa, Kessler, \& Spector, 2011). Therefore, in their quest to decrease job boredom, employees may partake in counterproductive work behaviors (Fisher, 1993). Counterproductive work behaviors may assume various forms and may be directed towards a variety of role-players within the employee's environment. Amongst others, it may include physical or psychological abuse against others, horseplay (e.g., playing practical jokes), and sabotaging organizational property (Bruursemaa et al., 2011; Spector et al., 2006).

Therefore, within the PE fit context, counterproductive work behaviors may be aimed at one's group, organization, or supervisor (or a combination of the three). The type of counterproductive work behavior employees engages in, and the recipient thereof may ultimately boil down to individual and situational differences. For example, with regard to quantitative underload, employees may display counterproductive behaviors towards their supervisors, when they perceive that their supervisors delegate less than the amount of work they are able to. Similarly, in terms of qualitative underload, employees may display counterproductive behaviors towards their group, when they feel that their fellow group members dump all the tedious tasks on them. When employees' abilities exceed their demands, positive outcomes (e.g., creativity) may 
Person-environment fit

also ensue under certain circumstances (e.g., Luksyte \& Spitzmueller, 2016). Therefore, the context of the employee is of vital importance.

Traditional fit research suggests that there should be a balance between individual and environmental characteristics, and excess on either characteristic is not desirable from an individual or organizational perspective. There are exceptions to this rule, however. Cable and Edwards (2004) found that employees whose supplies exceeded their needs (e.g., excess prestige), did not necessarily experience negative consequences. Instead, from an individual perspective, that excess supplies placed them in a prime position regarding NS fit (Cable \& Edwards, 2004). Similarly, Locke (1976) suggests that overpayment is less troublesome than underpayment. In fact, apart from shielding employees from harmful outcomes associated with misfit, overpayment can also positively influence employees' job satisfaction and provide access to material and psychological benefits (Lambert, Edwards, \& Cable, 2003).

Having an excess of supplies is not always beneficial though, as excess relationships may impede one's privacy (Edwards \& Rothbard, 1999). Consequently, employees may become irritable at the lack of personal boundaries. Similarly, excess autonomy may place additional demands on employees (e.g., more responsibility), interfering with their role clarity and direction (Warr, 1987). Therefore, the supply on which excess is experienced (and the severity thereof), may ultimately determine the type of outcome experienced (e.g., negative/neutral/positive). In contrast, when employees' needs exceed their supplies, it paves the way for demotivated, dissatisfied, and frustrated employees (French, Caplan, \& Harrison, 1982). Apart from being linked to intrinsic or extrinsic rewards, needs may also be emotionally, psychologically, or socially rooted. Consequently, the type of need where a deficit occurs, the severity thereof, and the perceived culprit responsible for the need deficit may ultimately determine how employees will react to NS 
Person-environment fit

misfit. For instance, when employees feel that their needs are not adequately fulfilled because of broken organizational promises (e.g., psychological contract breach), they may showcase attitudes and behaviors that negatively impact their organization (e.g., deviant behaviors) (Bordia, Restubog, \& Tang, 2008).

Based on the preceding discussion it is reasonable to suggest that different types (DA, NS, PG, PO, PS fit) and levels (fit/misfit) of fit may lead to different fit processes. This highlights the importance of giving the different fit dimensions the attention it deserves.

\section{Under what circumstances may it be acceptable to use one fit approach over another?}

Depending on the aim of one's study, several conditions may justify the selection of one fit approach over another. For example, when you want to gauge the prevalence rate of overall PE fit in your organization, broad fit measures could be more suitable than specific ones. In contrast, when you want to pinpoint possible intervention areas, more specific fit instruments could be appropriate. The nature of the outcome related to the fit dimension could also determine the most suitable approach. One should be cautious in making associations between target-specific antecedents (e.g., PG fit) and broad outcomes (e.g., overall job satisfaction), and vice versa (Fishbein \& Ajzen, 1975). Additionally, when you want to do comparative studies (e.g., when you want to test whether some fit dimensions predict particular outcomes better than others / when you want to investigate the inter-relationships between different types of fit) multidimensional fit measures, which assess various types and content dimensions of fit may be required. Different fit approaches (or combination of approaches) may uniquely yield important information under different circumstances. Therefore, the most appropriate fit approach to use ultimately depends on one's study objectives. 
Person-environment fit

How can misfit be approached? There is no universal blueprint for addressing misfit, as an approach that works for one employee may be highly ineffective or irrelevant to another one. The uniqueness of individuals (and the characteristics they possess), as well as the uniqueness of the environment in which they function, may offer an explanation for this. Therefore, depending on the dimension or content dimension on which misfit is experienced, and the type of misfit experienced (whether something is higher or lower than the desired amount), organizations and employees may approach misfit in several ways. From an organizational perspective, different strategies may eliminate the adverse consequences of misfit. For instance, training, development, coaching, and mentoring initiatives may counteract DA misfit; reward, recognition, and employee assistance programmes may stabilize NS misfit; and socialization-based efforts may neutralize PG, PO, and PS misfit.

From an individual perspective, employees are motivated to achieve, maintain, and regain fit (if lost) (Dawis \& Lofquist, 1984; Follmer et al., 2018, Yu, 2013). Therefore, various proactive and job altering behaviors could aid employees to escape the clutches of misfit. Job crafting is one way to alter one's job design, the social elements of one's job, or the way one thinks about one's job (Wrzesniewski \& Dutton, 2001). By purposefully altering various deterring aspects of one's environment and aligning it with one's personal characteristics (e.g., abilities, needs), better fit can be achieved (Berg, Dutton, \& Wrzesniewski, 2013). For instance, employees whose abilities exceed their demands could seek out additional responsibilities. Apart from creating better demands-abilities symmetry for themselves, this could alleviate some of the challenges faced by their co-workers. Similarly, employees whose supplies (e.g., excessive interpersonal contact) exceed their needs could limit the number of social exchanges at work. Although various factors may influence the extent to which employees can engage in certain behaviors (e.g., having little 
Person-environment fit

freedom to alter certain job aspects) or the degree to which organizations can aid employees (e.g., having a deficit on the training budget), a joint effort between individuals and organizations to address misfit should be desirable.

To what extent could employees' perceptions of fit be distorted? As employees may not have all the information at their disposal to make completely accurate judgments about their fit with aspects of their environment, their judgments may rely on inconsistent, unique, or recent information (e.g., Kahneman \& Tversky, 1972). Accordingly, certain fit delusions may occur. On the one hand, certain employees may have strong fit perceptions despite evidence suggesting otherwise. These employees may possess characteristics that detach them from the reality of their environment. This may include psychopathological factors such as personality disorders (e.g., schizoid personality disorder). Similarly, employees may overestimate their worth (e.g., narcissistic personality disorder) and be over-confident in their abilities to accomplish specific tasks.

On the other hand, certain employees may have strong misfit perceptions despite evidence suggesting otherwise. Psychopathological tendencies, such as being overly self-critical and perfectionistic, having low self-esteem, as well as being naturally pessimistic or paranoid may play a role here. Accordingly, it is reasonable to suggest that several factors may influence the accuracy of employees' fit perceptions. Due to the rising prevalence of psychopathology in the workplace, it may be worthwhile to investigate its impact on employees' perceptions of fit, how it may influence the importance employees attach to different types of fit (e.g., employees with a dependent personality disorder may place a larger emphasis on PG fit), and its importance in the broader context of fit. 
Person-environment fit

\section{Conclusion}

Although there may be incongruence regarding the direction of PE fit, its dimensionality, measurement, and the way forward (to name a few); one thing is for sure: we live in exciting times of fit research! To solve the PE fit conundrum, it may require researchers to fully comprehend every intricate detail involved in the process, which includes the individual and his or her environment (e.g., job, organization, group, and supervisor). Therefore, to truly grasp the concept of PE fit, its antecedents, outcomes, and the mechanisms which may interact or combine with it to explain other relationships; it may require a combined interdisciplinary, multidisciplinary, and transdisciplinary effort from scholars and practitioners that primarily focus on aspects related to fit. Although fit research is predominantly applied in organizational contexts, the investigation thereof should not be restricted to industrial/organizational psychology. Other fields could contribute equally to its full realization, as people are nested in various domains beyond their jobs or organizations. There is no need to reinvent the 'fit' wheel, it is just a matter of borrowing, integrating, and modifying the best aspects of existing frameworks (across various disciplines), and capitalize on what they have to offer (Edwards, 2008). It may sound ironic, but to make substantial progress in PE fit theory, researchers and practitioners need to 1) collectively equip themselves with the knowledge and abilities to combat the ever-increasing demands (conceptual and methodological limitations) associated with PE fit research; 2) satisfy their need for competence by successfully navigating through the abundant supply of fit-related literature; and 3) incorporate values (or set goals) that foster collaboration, creativity, critical thinking, and inclusiveness.

\section{Practical implications}

There are several important 'take-home messages' from fit literature, these include: 
Person-environment fit

PE fit and misfit are equally important constructs. To sufficiently understand the totality of PE interactions, one should be aware of its positive and negative aspects, as well as the different dimensions and content dimensions that could apply to a person's environment. Studying fit solely from a psychopathological, positive psychology, or positive organizational scholarship viewpoint will detract from the richness PE fit has to offer.

The multidimensionality of fit is non-negotiable. Various studies (e.g., Follmer et al., 2018) have shown that one may experience fit on one (or more) dimension, while simultaneously experiencing misfit with others. Similarly, other studies (e.g., Vogel \& Feldman, 2009, Yu, 2016) have shown the interrelatedness between different types of fit, and how different types of fit uniquely relate to outcomes (e.g., Harold et al., 2016). This necessitates the simultaneous investigation of multiple fit types.

Fit is a delicate balancing act between individual and environmental characteristics. Too much or too little fit should negatively influence employees and organizations alike. However, when one manages to find a balance between the two, it should conjure up a world of possibilities.

$>$ Not all fits are created equal. Where a specific type of fit may bring significant positive change for one employee, it may be completely irrelevant for another employee. Therefore, organizations should show genuine interest in the factors that make their employees 'tick' to suitably modify their assistance and offerings. Employees are the most valuable organizational asset, treat them accordingly!

Due to various reasons, a degree of misfit is inevitable, and organizations should compensate for that. Although not all types of misfit will detrimentally impact 
Person-environment fit

organizations or employees (e.g., being overpaid), a nonchalant attitude towards misfit may put organizations in precarious positions due to the offset of negative consequences.

Employees may respond differently to situations of fit or misfit. When experiencing misfit, some employees may defy the odds and actively craft their way towards better congruence, while other employees may succumb to their circumstances. Due to the uniqueness of employees' characteristics and their circumstances, employees' fit processes will hardly ever look the same. Therefore, organizations should shy away from using generic 'one-size fits all' approaches.

$>$ Fit is susceptible to change. Any change in one's environment may trigger reassessments of fit (e.g., Caldwell et al., 2004). Therefore, systems should be in place to continually evaluate and monitor fit.

Different types (DA, NS, PG, PO, PS fit) and levels (fit/misfit) of fit may lead to different fit processes (e.g., Harold et al., 2016). Therefore, organizations should be aware of the individual and environmental factors that may accompany different types and levels of fit as they may uniquely impact outcomes.

\section{Recommendations for future research}

In addition to the recommendations for future PE fit research emphasized by previous studies (e.g., Van Vianen, 2018), future studies could strive to answer the following questions through the utilization of diverse research methods:

What are the prevalence rate of fit and misfit across different countries, cultures, industries, occupations, and other relevant criteria?

To what extent will the phenomenon of misfit become more prevalent in the future? 
Person-environment fit

$>$ Is it safe to assume that certain types of fit will consistently have stronger associations with factors they are qualitatively related to?

Have we exhausted all the relevant content dimensions per fit facet?

$>$ Could PE fit perhaps predict general life outcomes (e.g., flourishing, life satisfaction, psychopathology) better since people's identities largely revolve around their work?

$>$ How often could perceptions of fit change?

Under what type of conditions will one type of fit be more suited than others?

$>$ Can fit in one domain instill a sense of confidence in people to handle misfit in other domains more effectively?

$>$ What will enable some employees to manage misfit better than others?

$>$ To what extent could specific policies (e.g., employment equity policies) influence designated employees' perceptions of fit?

To what extent is achieving person-environment fit the responsibility of the employee or the organization?

What can influence employees to have skewed fit perceptions?

$>$ What effect does constantly dealing with poor-fitting employees have on managers and other employees?

\section{References}

Adkins, C. L., Ravlin, E. C., \& Meglino, B. M. (1996). Value congruence between co-workers and its relationship to work outcomes. Group \& Organization Management, 21, 439-460. doi: $\underline{10.1177 / 1059601196214005}$ 
Person-environment fit

Andela, M., \& van der Doef, M. (2018). A comprehensive assessment of the person-environment fit dimensions and their relationships with work-related outcomes. Journal of Career Development, 0894845318789512. doi: $10.1177 / 0894845318789512$

Argyris, C. (1964). Integrating the individual and the organization. New York, NY: John Wiley $\&$ Sons, Inc.

Arthur, W., Jr., Bell, S. T., Villado, A. J., \& Doverspike, D. (2006). The use of person-organization fit in employment decision making: An assessment of its criterion-related validity. Journal of Applied Psychology, 91, 786-801. doi: 10.1037/0021-9010.91.4.786

Astakhova, M. N. (2016). Explaining the effects of perceived person-supervisor fit and personorganization fit on organizational commitment in the US and Japan. Journal of Business Research, 69(2), 956-963. doi: 10.1016/j.jbusres.2015.08.039

Baard, P. P., Deci, E. L., \& Ryan, R. M. (2004). Intrinsic need satisfaction: A motivational basis of performance and well-being in two work settings. Journal of Applied Social Psychology, 34, 2045-2068. doi: 10.1111/j.1559-1816.2004.tb02690.x

Bandura, A. (1986). Social foundations of thought and action: A social cognitive theory. Englewood Cliffs, NJ: Prentice Hall.

Beasley, C. R., Jason, L. A., \& Miller, S. A. (2012). The general environment fit scale: A factor analysis and test of convergent construct validity. American Journal of Community Psychology, 50, 64-76. doi: 10.1007/s10464-011-9480-8

Bell, S. T. (2007). Deep-level composition variables as predictors of team performance: A metaanalysis. Journal of Applied Psychology, 92(3), 595-615. doi: 10.1037/0021-9010.92.3.595 
Person-environment fit

Berg, J. M., Dutton, J. E., \& Wrzesniewski, A. (2013). Job crafting and meaningful work. In B. J. Dik, Z. S. Byrne, \& M. F. Steger (Eds.), Purpose and meaning in the workplace (pp. 81-104). Washington, DC, US: American Psychological Association. doi: $10.1037 / 14183-005$

Blustein, D. L. (2006). The psychology of working. Mahwah, NJ: Erlbaum.

Bordia, P., Restubog, S. L. D., \& Tang, R. L. (2008). When employees strike back: Investigating mediating mechanisms between psychological contract breach and workplace deviance. Journal of Applied Psychology,93(5), 1104-1117. doi: 10.1037/0021$\underline{9010.93 .5 .1104}$

Brkich, M., Jeffs, D., \& Carless, S. A. (2002). A global self-report measure of person-job fit. European Journal of Psychological Assessment, 18(1), 43-51. doi: 10.1027//1015$\underline{5759.18 .1 .43}$

Bruursema, K., Kessler, S. R., \& Spector, P. E. (2011). Bored employees misbehaving: The relationship between boredom and counterproductive work behaviour. Work \& Stress, 25(2), 93-107. doi: $\underline{10.1080 / 02678373.2011 .596670}$

Byrne, D. (1971). The attraction paradigm. New York, NY: Academic Press.

Cable, D. M., \& DeRue, D. S. (2002). The convergent and discriminant validity of subjective fit perceptions. Journal of Applied Psychology, 87(5), 875-884. doi: 10.1037/0021$\underline{9010.87 .5 .875}$

Cable, D. M., \& Edwards, J. R. (2004). Complementary and supplementary fit: A theoretical and empirical integration. Journal of Applied Psychology, 89, 822-834. doi: 10.1037/0021$\underline{9010.89 .5 .822}$ 
Person-environment fit

Cable, D. M., \& Judge, T. A. (1996). Person-organization fit, job choice decisions, and organizational entry. Organizational Behavior \& Human Decision Processes, 67, 294-311. doi: $\underline{10.1006 / \text { obhd.1996.0081 }}$

Caldwell, S. D., Herold, D. M., \& Fedor, D. B. (2004). Toward an understanding of the relationships among organizational change, individual differences, and changes in personenvironment fit: A cross-level study. Journal of Applied Psychology, 89(5), 868-882. doi: $\underline{10.1037 / 0021-9010.89 .5 .868}$

Carver, C. S., \& Scheier, M. F. (2000). Autonomy and self-regulation. Psychological Inquiry, 11, 284-291.

Cennamo, L., \& Gardner, D. (2008). Generational differences in work values, outcomes and person-organisation values fit. Journal of Managerial Psychology, 23(8), 891-906. doi: $\underline{10.1108 / 02683940810904385}$

Chuang, A., Hsu, R. S., Wang, A. C., \& Judge, T. A. (2015). Does West “fit” with East? In search of a Chinese model of person-environment fit. Academy of Management Journal, 58, 480510. doi: $\underline{10.5465 / \mathrm{amj} .2012 .1076}$

Chuang, A., Judge, T. A., \& Liaw, Y. J. (2012). Transformational leadership and customer service: A moderated mediation model of negative affectivity and emotion regulation. European Journal of Work and Organizational Psychology, 21, 28-56. doi: $\underline{10.1080 / 1359432 X .2010 .532911}$

Chuang, A., Shen, C., \& Judge, T. A. (2016). Development of a multidimensional instrument of person-environment fit: The perceived person-environment fit scale (PPEFS). Applied Psychology: An International Review, 65, 66-98. doi: 10.1111/apps.12036 
Person-environment fit

Darrow, J. B., \& Behrend, T. S. (2017). Person-environment fit is a formative construct. Journal of Vocational Behavior, 103, 117-131. doi: 10.1016/j.jvb.2017.08.007

Dawis, R. V., \& Lofquist, L. H. (1984). A psychological theory of adjustment. Minneapolis, MN: University of Minnesota Press.

de Jonge, J., \& Dormann, C. (2006). Stressors, resources, and strain at work: A longitudinal test of the triple-match principle. Journal of Applied Psychology, 91, 1359-1374. doi: $\underline{10.1037 / 0021-9010.91 .5 .1359}$

Deci, E. L., \& Ryan, R. M. (1985). Intrinsic motivation and self-determination in human behavior. New York, NY: Plenum. doi: 10.1007/978-1-4899-2271-7

Demerouti, E., \& Bakker, A. B. (2011). The job demands-resources model: Challenges for future research. SA Journal of Industrial Psychology, 37(2), 01-09. doi: 10.4102/sajip.v37i2.974

Diefendorff, J. M., Greguras, G. J., \& Fleenor, J. (2016). Perceived emotional demands-abilities fit. Applied Psychology, 65(1), 2-37. doi: 10.1111/apps.12034

DiMarco, N. (1974). Supervisor-subordinate life style and interpersonal need compatibilities as determinants of subordinate's attitudes toward the supervisor. Academy of Management Journal, 17, 575-578. doi: 10.2307/254661

DiMarco, N. (1975). Life style, work group structure, compatibility, and job satisfaction. Academy of Management Journal, 18, 313-322.

Duffy, R. D., Blustein, D. L., Diemer, M. A., \& Autin, K. L. (2016). The psychology of working theory. Journal of Counseling Psychology, 63, 127-148. doi: $\underline{10.1037 / \mathrm{cou} 0000140}$

Edwards, J. A., \& Billsberry, J. (2010). Testing a multidimensional theory of person-environment fit. Journal of Managerial Issues, 4, 476-493. 
Person-environment fit

Edwards, J. R. (2008). Person-environment fit in organizations: An assessment of theoretical progress. Academy of Management Annals, 2(1), 167-230. doi: $\underline{10.5465 / 19416520802211503}$

Edwards, J. R. (1991). Person-job fit: A conceptual integration, literature review, and methodological critique. In C. L. Cooper \& I. T. Robertson (Eds.), International review of industrial and organizational psychology (vol. 6, pp. 283-357). New York, NY: Wiley.

Edwards, J. R., \& Rothbard, N. P. (1999). Work and family stress and well-being: An examination of person-environment fit in the work and family domains. Organizational Behavior and Human Decision Processes, 77, 85-129. doi:10.1006/obhd.1998.2813

Edwards, J. R., Cable, D. M., Williamson, I. O., Lambert, L. S., \& Shipp, A. J. (2006). The phenomenology of fit: Linking the person and environment to the subjective experience of person-environment fit. Journal of Applied Psychology, 91, 802-827. doi:10.1037/0021$\underline{9010.91 .4 .802}$

Fishbein, M., \& Ajzen, I. (1975). Belief, attitude, intention, and behavior: An introduction to theory and research. Reading, MA: Addison-Wesley.

Fisher, C. D. (1993). Boredom at work: A neglected concept. Human Relations, 46, 395-418. doi: $\underline{10.1177 / 001872679304600305}$

Follmer, E. H., Talbot, D. L., Kristof-Brown, A. L., Astrove, S. L., \& Billsberry, J. (2018). Resolution, relief, and resignation: A qualitative study of responses to misfit at work. Academy of Management Journal, 61(2), 440-465. doi: 10.5465/amj.2014.0566

French, J. R. P., Caplan, R. D., \& Harrison, R. V. (1982). The mechanisms of job stress and strain. London, UK: Wiley. 
Person-environment fit

Goldberg, L. R. (1990). An alternative "description of personality": The big-five factor structure. Journal of Personality and Social Psychology,59(6), 1216-1229. doi: $\underline{10.1037 / 0022-3514.59 .6 .1216}$

Greguras, G. J., \& Diefendorff, J. M. (2009). Different fits satisfy different needs: Linking personenvironment fit to employee commitment and performance using self-determination theory. Journal of Applied Psychology, 94, 465-477. doi: 10.1037/a0014068

Harold, C. M., Oh, I. S., Holtz, B. C., Han, S., \& Giacalone, R. A. (2016). Fit and frustration as drivers of targeted counterproductive work behaviors: A multifoci perspective. Journal of Applied Psychology, 101(11), 1513-1535. doi: $\underline{10.1037 / a p 10000150}$

Herdman, A. O., \& Carlson, K. D. (2009). Global perceptions of the fit between person and work environment (P-E fit): Development and initial validation of a new measure. Psychological Reports, 105, 1181-1195. doi: 10.2466/PR0.105.F.1181-1195

Hinkle, R. K., \& Choi, N. (2009). Measuring person-environment fit: A further validation of the perceived fit scale. International Journal of Selection and Assessment, 17(3), 324-328. doi: $\underline{10.1111 / j .1468-2389.2009 .00474 . x}$

Hoffman, B. J., \& Woehr, D. J. (2006). A quantitative review of the relationship between personorganization fit and behavioral outcomes. Journal of Vocational Behavior, 68, 389-399. doi:

\section{$\underline{10.1016 / j . j v b .2005 .08 .003}$}

Hoffman, B. J., Bynum, B. H., Piccolo, R. F., \& Sutton, A. W. (2011). Person-organization value congruence: How transformational leaders influence work group effectiveness. Academy of Management Journal, 54, 779-796. doi: 10.5465/amj.2011.64870139

Hofstede, G. (1980). Culture's consequences: International differences in work-related values. Beverly Hills, CA: Sage. 
Person-environment fit

Holland, J. L. (1997). Making vocational choices: A theory of vocational personalities and work environments (3rd ed.). Lutz, FL: Psychological Assessment Resources.

Jansen, K. J., \& Kristof-Brown, A. (2006). Toward a multidimensional theory of personenvironment fit. Journal of Managerial Issues, 18, 193-212.

Kahneman, D., \& Tversky, A. (1972). Subjective probability: A judgment of representativeness. Cognitive Psychology, 3, 430-454. doi: 10.1016/0010-0285(72)90016-3

Kammeyer-Mueller, J. D., Schilpzand, P., \& Rubenstein, A. L. (2013). Dyadic fit and the process of organizational socialization. In A. L. Kristof-Brown \& J. Billsberry (Eds.), New directions in organizational fit (pp. 50-73). Sussex, UK: John Wiley \& Sons. doi: $\underline{10.1002 / 9781118320853 . c h 3}$

Kristof, A. L. (1996). Person-organization fit: An integrative review of its conceptualizations, measurement, and implications. Personnel Psychology, 49, 1-49. doi: 10.1111/j.17446570.1996.tb01790.x

Kristof-Brown, A. L., \& Stevens, C. K. (2001). Goal congruence in project teams: Does the fit between members' personal mastery and performance goals matter? Journal of Applied Psychology, 86, 1083-1095. doi: 10.1037/0021-9010.86.6.1083

Kristof-Brown, A. L., Jansen, K. J., \& Colbert, A. E. (2002). A policy-capturing study of the simultaneous effects of fit with jobs, groups, and organizations. Journal of Applied Psychology, 87, 985-993. doi: 10.1037/0021-9010.87.5.985

Kristof-Brown, A. L., Zimmerman, R. D., \& Johnson, E. C. (2005). Consequences of individuals' fit at work: A meta-analysis of person-job, person-organization, person-group, and personsupervisor fit. Personnel Psychology, 58, 281-342. doi: 10.1111/j.1744-6570.2005.00672.x 
Person-environment fit

Lambert, L. S., Edwards, J. R., \& Cable, D. M. (2003). Breach and fulfillment of the psychological contract: A comparison of traditional and expanded views. Personnel Psychology, 56, 895934. doi: $10.1111 / \mathrm{j} .1744-6570.2003 . t b 00244 . x$

Lauver, K. J., \& Kristof-Brown, A. L. (2001). Distinguishing between employees' perceptions of person-job and person-organization fit. Journal of Vocational Behavior, 59, 454-470. doi: $\underline{10.1006 / j v b e .2001 .1807}$

Lewin K. (1951). Formalization and progress in psychology. In Cartwright D (Ed.), Field theory in social science. New York, NY: Harper.

Locke, E. A. (1976). The nature and causes of job satisfaction. In M. D. Dunnette (Ed.), Handbook of industrial and organizational psychology (pp. 1297-1343). Chicago, IL: Rand McNally.

Luksyte, A., \& Spitzmueller, C. (2016). When are overqualified employees creative? It depends on contextual factors. Journal of Organizational Behavior,37(5), 635-653. doi: $\underline{10.1002 / j o b .2054}$

Marstand, A. F., Martin, R., \& Epitropaki, O. (2017). Complementary person-supervisor fit: An investigation of supplies-values (S-V) fit, leader-member exchange (LMX) and work outcomes. The Leadership Quarterly, 28(3), 418-437. doi: 10.1016/j.leaqua.2016.10.008

McCrae, R. R., \& Costa Jr., P. T. (1999). A five-factor theory of personality. In L. A. Pervin \& O. P. John (Eds.), Handbook of Personality Psychology (pp. 139-153). New York, NY: Guilford. Meglino, B. M., \& Ravlin, E. C. (1998). Individual values in organizations: Concepts, controversies, and research. Journal of Management, 24, 351-389. doi: $\underline{10.1177 / 014920639802400304}$ 
Person-environment fit

Miller, L., \& Hayward, R. (2006). New jobs, old occupational stereotypes: Gender and jobs in the new economy. Journal of Education and Work, 19(1), 67-93. doi: $\underline{10.1080 / 13639080500523000}$

Muchinsky, P. M., \& Monahan, C. J. (1987). What is person-environment congruence? Supplementary versus complementary models of fit. Journal of Vocational Behavior, 31, 268-277. doi: 10.1016/0001-8791(87)90043-1

Oh, I. S., Guay, R. P., Kim, K., Harold, C. M., Lee, J. H., Heo, C.G., \& Shin, K. H. (2014). Fit happens globally: A meta-analytic comparison of the relationships of person-environment fit dimensions with work attitudes and performance across East Asia, Europe, and North America. Personnel Psychology, 67, 99-152. doi: 10.1111/peps.12026

Park, H. I., Beehr, T. A., Han, K., \& Grebner, S. I. (2012). Demands-abilities fit and psychological strain: Moderating effects of personality. International Journal of Stress Management, 19, 133. doi: $\underline{10.1037 / \mathrm{a} 0026852}$

Piasentin, K. A., \& Chapman, D. S. (2006). Subjective person-organization fit: Bridging the gap between conceptualization and measurement. Journal of Vocational Behavior, 69, 202-221. doi: $10.1016 /$ j.jvb.2006.05.001

Ryan, R. M., \& Deci, E. L. (2000). Self-determination theory and the facilitation of intrinsic motivation, social development, and well-being. American Psychologist, 55, 68-78. doi: $\underline{10.1037 / 0003-066 X .55 .1 .68}$

Ryff, C. D., \& Keyes, C. L. M. (1995). The structure of psychological well-being revisited. Journal of Personality and Social Psychology, 69, 719-727. doi: 10.1037/0022-3514.69.4.719 
Person-environment fit

Saks, A. M., \& Ashforth, B. E. (1997). A longitudinal investigation of the relationships between job information sources, applicant perceptions of fit, and work outcomes. Personnel Psychology, 50, 395-426. doi: 10.1111/j.1744-6570.1997.tb00913.x

Salmivalli, C., Lagerspetz, K. M. J., Björkqvist, K., Österman, K., \& Kaukiainen, A. (1996). Bullying as a group process: Participant roles and their relations to social status within the group. Aggressive Behavior, 22, 1-15. doi: 10.1002/(SICI)1098-2337(1996)22:1<1::AID$\underline{\mathrm{AB} 1>3.0 . \mathrm{CO} ; 2-\mathrm{T}}$

Schaubroeck, J., \& Lam, S. S. K. (2002). How similarity to peers and supervisor influences organizational advancement in different cultures. Academy of Management Journal, 45, $1120-1136$.

Schneider, B. (1987). The people make the place. Personnel Psychology, 40, 437-453. doi: 10.1111/j.1744-6570.1987.tb00609.x

Schneider, B., Goldstein, H. W., \& Smith, D. B. (1995). The ASA framework: An update. Personnel Psychology, 48, 747-773. doi: 10.1111/j.1744-6570.1995.tb01780.x

Schwartz, S. H. (1999). A theory of cultural values and some implications for work. Applied psychology, 48(1), 23-47. doi: 10.1111/j.1464-0597.1999.tb00047.x

Seong, J. Y., \& Kristof-Brown, A. L. (2012). Testing multidimensional models of person-group fit. Journal of Managerial Psychology, 27, 536-556. doi: $\underline{\text { 10.1108/02683941211252419 }}$

Seong, J. Y., Kristof-Brown, A. L., Park, W. W., Hong, D. S., \& Shin, Y. (2015). Person-group fit: Diversity antecedents, proximal outcomes, and performance at the group level. Journal of Management, 41(4), 1184-1213. doi: 10.1177/0149206312453738

Sheldon, K. M., Ryan, R. M., Rawsthorne, L. J., \& Ilardi, B. (1997). Trait self and true self: Crossrole variation in the Big-Five personality traits and its relations with psychological 
Person-environment fit

authenticity and subjective well-being. Journal of Personality and Social Psychology, 73, 1380-1393. doi: $\underline{10.1037 / 0022-3514.73 .6 .1380}$

Spector, P.E., Fox, S., Penney, L. M., Bruursema, K., Goh, A., \& Kessler, S. (2006). The dimensionality of counterproductivity: Are all counterproductive behaviors created equal? Journal of Vocational Behavior, 68, 446-460. doi: 10.1016/j.jvb.2005.10.005

Swann, W. B., Jr., Stein-Seroussi, A., \& Giesler, R. B. (1992). Why people self-verify. Journal of Personality and Social Psychology, 62, 392-401. doi: 10.1037/0022-3514.62.3.392

Tak J. (2011). Relationships between various person-environment fit types and employee withdrawal behavior: A longitudinal study. Journal of Vocational Behavior, 78, 315-320. doi: $\underline{10.1016 / j . j v b .2010 .11 .006}$

Thomson, W. C., \& Wendt, J. C. (1995). Contribution of hardiness and school climate to alienation experienced by student teachers. The Journal of Educational Research, 88(5), 269-274. doi: $\underline{10.1080 / 00220671.1995 .9941310}$

Tims, M., Derks, D., \& Bakker, A. B. (2016). Job crafting and its relationships with person-job fit and meaningfulness: A three-wave study. Journal of Vocational Behavior, 92, 44-53. doi: $\underline{10.1016 / j . j v b .2015 .11 .007}$

Turban, D. B., \& Jones, A. P. (1988). Supervisor-subordinate similarity: Types, effects, and mechanisms. Journal of Applied Psychology, 73, 228-234. doi: $\underline{\text { 10.1037/0021-9010.73.2.228 }}$

Van den Bosch, R., \& Taris, T. W. (2014). The authentic worker's well-being and performance: The relationship between authenticity at work, well-being, and work outcomes. The Journal of Psychology, 148(6), 659-681. doi: 10.1080/00223980.2013.820684 
Person-environment fit

Van Vianen, A. E. (2018). Person-Environment Fit: A Review of Its Basic Tenets. Annual Review of Organizational Psychology and Organizational Behavior, 5, 75-101. doi: 10.1146/annurev-orgpsych-032117-104702

Vancouver, J. B., \& Schmitt, N. W. (1991). An exploratory examination of person-organization fit: Organizational goal congruence. Personnel Psychology, 44, 333-352. doi: $\underline{10.1111 / j .1744-6570.1991 . t b 00962 . x}$

Verquer, M. L., Beehr, T. A., \& Wagner, S. H. (2003). A meta-analysis of relations between person-organization fit and work attitudes. Journal of Vocational Behavior, 63, 473-489. doi: $\underline{10.1016 / \mathrm{S} 0001-8791(02) 00036-2}$

Vogel, R. M., \& Feldman, D. C. (2009). Integrating the levels of person-environment fit: The roles of vocational fit and group fit. Journal of Vocational Behavior,75(1), 68-81. doi: 10.1016/j.jvb.2009.03.007

Warr, P. (1987). Work, unemployment, and mental health. Oxford: Clarendon Press.

Witt, L. A. (1998). Enhancing goal congruence: A solution to organizational politics. Journal of Applied Psychology, 83, 666-674. doi: 10.1037/0021-9010.83.4.666

Wrzesniewski, A., \& Dutton, J. E. (2001). Crafting a job: Revisioning employees as active crafters of their work. Academy of Management Review, 26(2), 179-201. doi: $\underline{10.5465 / \mathrm{amr} .2001 .4378011}$

Wrzesniewski, A., McCauley, C., Rozin, P., \& Schwartz, B. (1997). Jobs, careers, and callings: People's relations to their work. Journal of Research in Personality, 31, 21-33. doi: $\underline{10.1006 / j r p e .1997 .2162}$

Yu, K. Y. T. (2016). Inter-relationships among different types of person-environment fit and job satisfaction. Applied Psychology, 65(1), 38-65. doi: 10.1111/apps.12035 
Person-environment fit

Yu, K. Y. T. (2013). A motivational model of person-environment fit: Psychological motives as drivers of change. In A. L. Kristof-Brown \& J. Billsberry (Eds.), Organizational fit: Key issues and new directions (pp. 19-49). Chichester, UK: Wiley-Blackwell. 